\title{
Climatological Nephropathy: An Overview
}

\author{
Priya Jaswal $^{1}$, Priyanka ${ }^{2}$, Jhilli Basu ${ }^{3}$ \\ ${ }^{1}$ Pharmacologist, Department of Pharmacology, Maharishi Markandeshwar Medical College \& Hospital, Solan, \\ Himachal Pradesh \\ ${ }^{2}$ Assistant Professor, Sri Sai Institute of Pharmacy, Pathankot, Himachal Pradesh \\ ${ }^{3}$ Assistant Professor, Department of Pharmacology, Maharishi Markandeshwar Medical College \& Hospital, \\ Solan, Himachal Pradesh \\ Corresponding Author: Priya Jaswal
}

\begin{abstract}
Globally hike in temperature provokes the heat waves, results in heat stress and becomes a silent health peril to the existing population. Today, heat stress or climatological stress is one of the dominant pathological conditions which comes in focus when the body means of handling its thermoregulatory function starts to fail, show its associated symptoms followed by eventual loss of consciousness and finally death. The condition of heat stress along with intermittent dehydration worsens the renal damage and enhances the risk of Acute Kidney Injury (AKI), results in chronic kidney disease (CKD). Therefore, CKD comes up as a leading cause of death, specifically in those patients having long-lasting medical conditions like heart problem, hypertension, diabetes and obesity etc. High temperature, work rate, humidity and working time wearing accessories, all become mitigating factors for causing heat stress. Distinguish molecular ups and downs specifically decrease production of uric acid (polyol-fructokinase pathway), increase ROS (oxidative stress), intracellular $\mathrm{Ca} 2+$ overload (mitochondrial dysfunctioning) and decrease NO (vascular endothelial dysfunctioning) has been responsible for the severe outcomes of Climatological Nephropathy $(\mathrm{CN})$ or Heat Stress Nephropathy (HSN). However, prevention is the best approach to dealing with heat-related illness, therefore, the Government established some valuable policies as a preventive measures. This review epitomizes the alarming outcomes of the heat stress followed by recurrent dehydration and also enlightened the global talk of HSN, pathogenicity, molecular level peculiarities and recommended measures for HSN.
\end{abstract}

Keywords: Acute Kidney Injury, Chronic Kidney Disease, Nephropathy, Mitochondrial Dysfunctioning.

\section{INTRODUCTION}

Heat stress, the grievous form of heat illness characterized by the lifethreatening conditions, conjoin by ascent in core temperature $(\mathrm{Tc})$ that results from an inability of a body to dissipate excess heat to the environment. ${ }^{1}$ Increasing worldwide temperatures are now well documented, therefore, WHO states that global warming becomes a massive threat to the future of the planet. $^{2}$ The global temperature increase in the last 50 years approximates $0.8{ }^{\circ} \mathrm{C}^{3}$ that markedly escalates the extreme heat events, designated as heat waves. ${ }^{4}$ Our day to day life, excessive heat exposures are not only an environmental threat but also an occupational hazard for those countless workers who work in such hot conditions. ${ }^{5}$ The problem of heat stress is particularly present at rural areas of Central America, India, Sri Lanka and Egypt where young working men are exposed to extreme heat conditions on a routine earning basis ${ }^{6}$, Hence, this condition of nephropathy is also known as Mesoamerican Nephropathy or Chronic Kidney Disease of unknown origin $(\mathrm{CKDu})$. Climatological studies in India has been very challenging not because of the 
presence of distinct annual weather criteria i.e. spring, summer, autumn, and winter but also due to its geographical variability's. ${ }^{7}$ Heat Stress is the mutual collaboration between environmental phenomenon and metabolic heat processes which shoot up the Core Body Temperature (CBT) of an individual that may potentially slow down the physiological processes. ${ }^{8}$ Disastrous physiological changes our in our body due to heat stress, that may result in multiple heat-related diseases like heatstroke, heat cramp, heat exhaustion and death. Heat stress in occupational settings or areas like glass and metal factories, agriculture sector, mining and construction work areas has become a very much familiar hazardous situation depending upon the severity and intensity of exposure. ${ }^{9,} 10$ Workplace humidity is also a contributing factor towards heat stress and workers such as firemen, soldiers, asbestos workers, sandblasters, tank cleaners etc., whose work demands wearing insulated clothing can undergo higher stress due to additional insulation. ${ }^{11}$ Unlimited heat exposure in workplaces may result in multiple health crisis ranges from mild to moderate skin problems and ultimately fatal heatstroke. Dehydration, sweating, salt loss, loss of perceptual and motor functions, heat exhaustion or increased accident risk, all these become some warning features of heat stress. Among these all alarming symptoms, our increased body temperature or core temperature i.e. $>37^{\circ} \mathrm{C}$ becomes the centre of attraction with different pathological temperature limits i.e. $>38^{\circ} \mathrm{C}$ (heat strain), $>39^{\circ} \mathrm{C}$ (dangerous level) and $>40^{\circ} \mathrm{C}$ (heat stroke, loss of consciousness, death). ${ }^{8}$ Besides this, continuous heat exposures along with dehydration worsen the renal status of an individual ${ }^{9}$ and also provoke preexisting chronic health conditions such as respiratory, cardiovascular diseases and kidney diseases. ${ }^{12,13,14}$ Various molecular level strategies become the backbone of heat stress nephropathy and it is triggered by the activation of $\operatorname{ROS}^{15,16}$, Increase iNOS and NO production ${ }^{17,18}$, downregulation of ATP and through over activation of NF-KB, Endothelin-1. ${ }^{19,20}$ One of the consequences of heat stress and dehydration is the development of elevated serum osmolarity by polyol-fructokinase pathway that may also cause renal injury. ${ }^{21}$ The most common predictors of heat stress nephropathy include decreased glomerular filtration, increased creatinine, uric acid, blood urea nitrogen (BUN) or electrolyte changes. ${ }^{22}$ Prolonged dehydration along with heat stress disturbs the homeostatic balance of the body results in decreased skin blood flow, elevated CBT, decreased sweat rate ${ }^{6}$ and profound increase in heart rate which may lead to sympathovagal imbalance if not treated earlier. ${ }^{23}$ From a therapeutic point of view, prevention on early stages should be possible by getting portable water supplies, scheduled resting periods and mobile shaded tents for those who work in hot conditions. $^{24,25}$ Pharmacological approaches along with electrolyte balancing may also become an early intervention to downregulate the progression of acute kidney injury $(\mathrm{AKI}){ }^{26}$

\section{Planetary Journey of HSN}

Earth's climate and global variations are interlinked, resulting in climate change which occurs at various timescales and meteorological parameter like temperature, rainfall, cloudiness, etc. which largely contributes towards energy production and converts into disastrous heat waves as depicted in Figure: $\mathbf{1}^{27}$. Due to geographical heterogeneity, the earth's temperature has been increased by about 0.7 ${ }^{\circ} \mathrm{C}$ in the twentieth century and progressed day by day during the past 50 years. ${ }^{28}$ Worldwide studies suggest that due to climate change in 2015 more than 175 million people were affected ${ }^{29}$ e.g. Spain, due to its geographical location becomes more vulnerable to climate variations expected that in the last third of the century its summer temperatures will be $5-7 \circ \mathrm{C}$ higher. $^{30}$ Heat wave that create environmental violence in Europe 2003 became fatal for more than 70,000 people 
across the continent consisting 6500 deaths in Spain and with more than 14,729 deaths in France $^{6}$ most of whom were elderly people dehydrated with renal failure. ${ }^{1,31,32}$ According to environmental and metrological data, it's estimated that in 2003 approximately 70,000 additional deaths occurred over the summer months in Western Europe ${ }^{33}$ and Australia, 4336 people died between 1803 and 2002 as a consequence of drastic heat waves. Specific heat wave events in the USA are estimated to cause about 400 deaths per year since 1998, Queensland standby with 22 deaths and 350 injuries in January 2000 and with
12 deaths and 221 hospitalizations in February $2004^{34}$ and the Northern hemisphere has also been suffered with heat waves tragedy, mortality rate ranging from $4 \%$ to $142 \%$. Therefore, heat waves have caused significant fatality throughout the world, including Chicago in $1995^{35}$, Andhra Pradesh in 2014 and $2015^{36,37}$ and Karachi, Pakistan in 2015. ${ }^{23}$ The collaboration of heat stress, dehydration, and physical activity enforce challenge for physical adjustment and disturbs the homeostasis of the body leading to impaired to tolerance to work resulting in increased risks of heat injuries. ${ }^{9}$

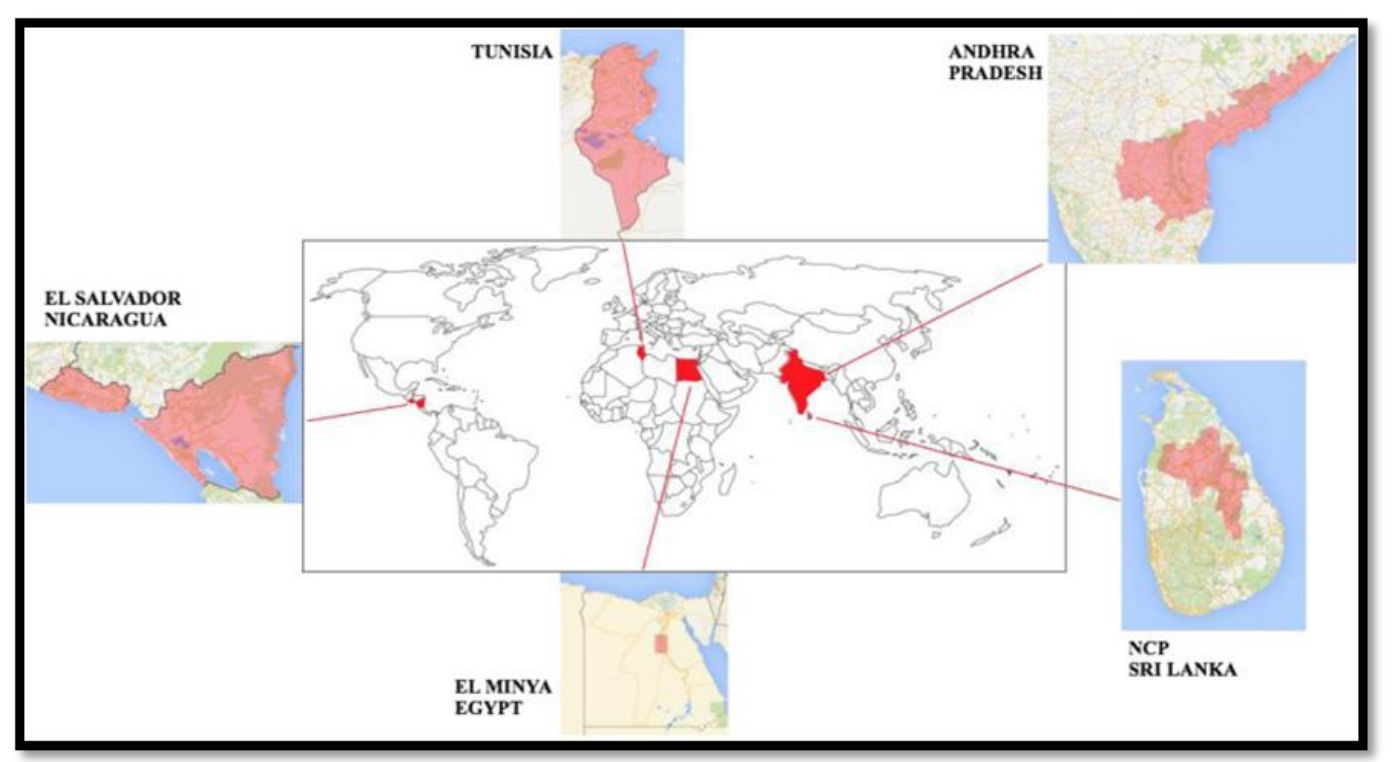

Figure 1: Universal Map Indicating Areas with High Prevalence of CKDu. https://commons.wikimedia.org/wiki/File:The_World_map.png, https://www.google.co.uk/maps/place/Tunisia, https://www.google.co.uk/maps/place/Andhra+Pradesh, https://www.google.co.uk/maps/place/Sri+Lanka, https://www.google.co.uk/maps/place/Egypt, https://www.google.co.uk/maps/place/Nicaragua

\section{Heat Stress Hypothesis}

Even though dehydration has not been considered a major risk factor for $\mathrm{CKD}$, it is well known to adversely affect the kidney functions. It's all because of dehydration urinary concentration increase due to vasopressin activation and on the other hand serum osmolarity increase due to the loss of body fluid. ${ }^{38}$ However, this is experimentally proved that the long term or repeated attacks of heat stress accompanied by dehydration or volume depletion can cause ischemic kidney injury and which may ultimately lead to permanent kidney damage and $\mathrm{CKD}^{39,40}$ as shown in Figure:
2. Heat illness is characterized by loss of sweating, confusion leading to coma, fast pulse, low blood pressure, heart failure and kidney failure. Patients with heat illness will not be able to notice the change so it's important that family members be alert for changes when the mercury begins to rise, especially in the very young and the very old who are most susceptible to heat illness. Heat stress nephropathy associated with multifactorial risk factors like occupational, personal socioeconomic and climate factors that may increase the risk of $\mathrm{CKDu}$ is summarized in Figure: 3. 


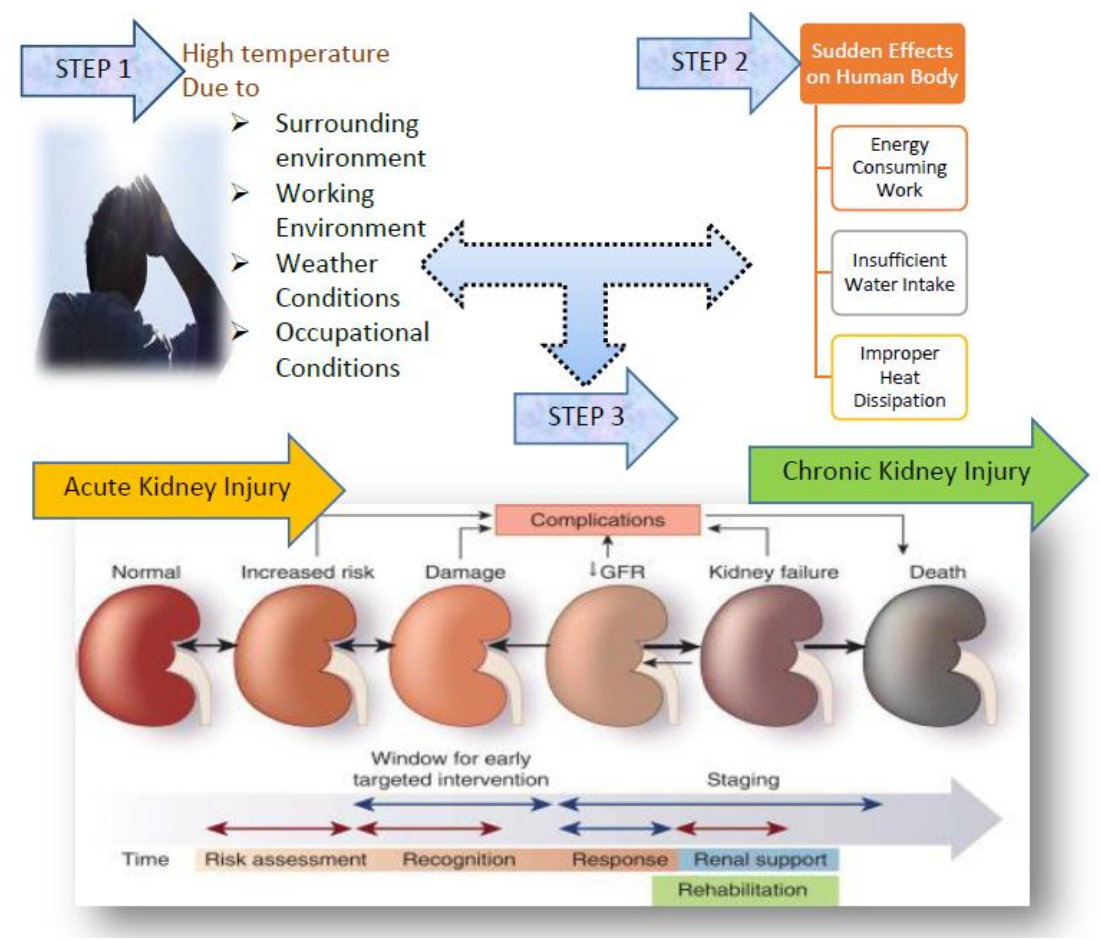

Figure 2. Hypothesized Climatological Nephropathy

Infants and the very young have a high surface area to mass ratio and will absorb heat from the environment more readily. However, Obesity and alcohol abuse are very frequent risk factors for heat illness. Numerous scientists believe that heat-stress nephropathy results from extreme occupational heat stress and repeated dehydration play a key role in the pathophysiology of Mesoamerican nephropathy, and this may become a valid point for CKDu in other CKDu hotspots. ${ }^{39}$, $41,42,43$

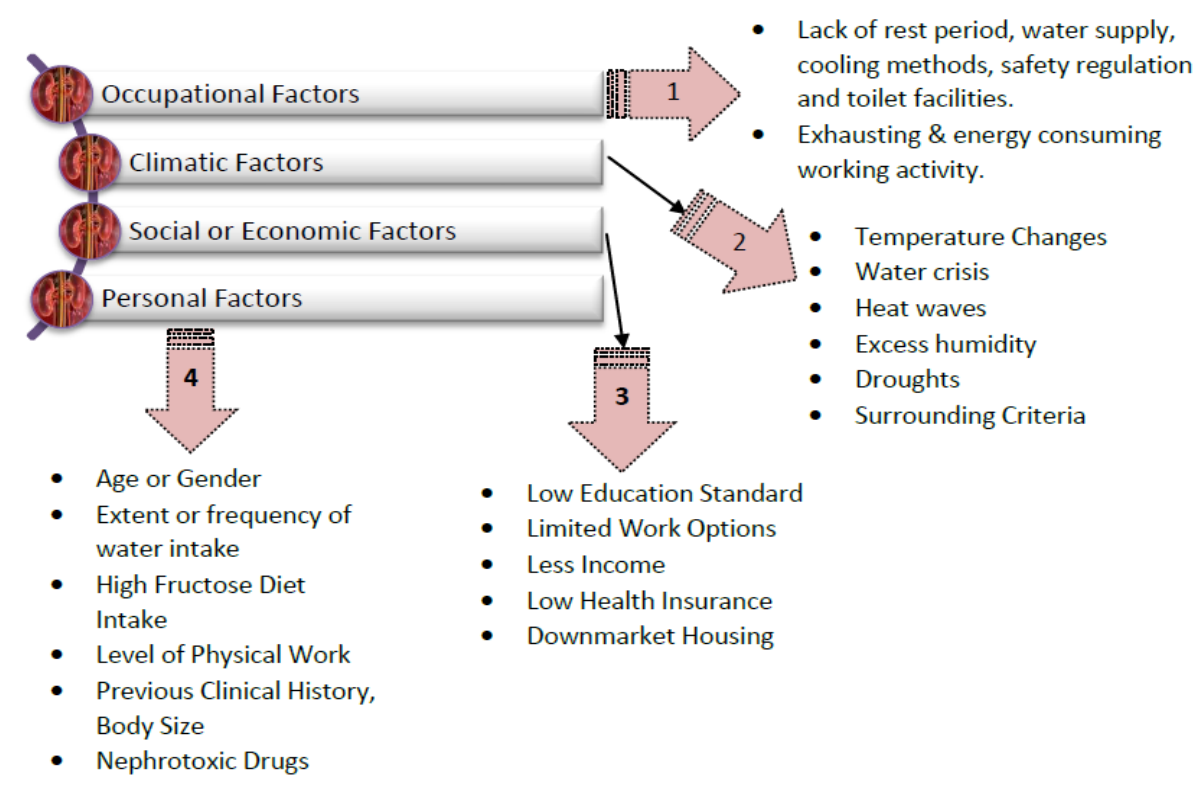

Figure 3. Risk Factor associated with Climatological Nephropathy

(https://els-jbs-prod-cdn.jbs.elsevierhealth.com/cms/attachment/d23f4a7b-6ceb-4377-b68c-318f49a9e3e5/gr3.jpg)

\section{Pathophysiology of HSN}

Chronic kidney disease is identified by proteinuria, serum urea, creatinine retention, increase blood pressure and imbalance in renal perfusion that results in the development of glomerular hypertension 
and hypertrophy, mesangial cells proliferation, extracellular matrix (EM) overproduction and irreversible changes in glomerular and tubular architecture that disturbs the behave of the functional unit of kidney i.e. nephron ${ }^{44,45}$ Figure: $4^{46}$. Remarkably, the involvement of the tubulointerstitial compartment has been closely correlated with the extent of kidney failure. ${ }^{44,45,47}$ As the working pressure in the kidney increase, more filtering units are injured, that overburdened the remaining nephrons and finally our filtering units surrender due to overload in a positive feedback cycle causes such a pathogenic conditions like global glomerulosclerosis (GS), tubular atrophy (TA), interstitial fibrosis, peritubular capillary rarefaction, and progressive renal function loss. $44,45,48$ The activation of the renin-angiotensinaldosterone system (RAAS) is one of the key components that can stimulate CKD progression. ${ }^{45}$ Traditionally, RAAS coming under an endocrine system, use as a controlling centre for blood pressure, even in situations of hypovolemia. ${ }^{49}$ Renin hormone manufactured by the renal juxtaglomerular cells, endorse the conversion of angiotensinogen into angiotensin I (Ang I) followed by further cleaved through Angiotensin-converting enzyme (ACE) into its active form, the Angiotensin II (Ang II). Furthermore, Ang II binds to its specific receptors (AT1) in the adrenal cortex, resulting in the release of aldosterone and this mineralocorticoid steroid promotes renal and systemic vasoconstriction and tubular sodium conservation uplift the blood pressure. ${ }^{45,49}$ In recent years, RAAS became more and more complex due to the identification of many novel compounds, such as the enzyme chymase, having the same function like ACE, the biologically active peptides angiotensin III, IV and several different Ang II receptors (AT2, AT4, among others).

Due to this complexity in RAAS, intracellular downstream system is activated by Ang II, and can trigger the various physiological responses. ${ }^{48,49}$ RAAS became overexcited during renal damage $51,52,53$ therefore, Ang II is the main culprit related to inflammation leading to chronic nephropathy. ${ }^{54,55}$ The increment of dendritic cells (DCs) in the renal parenchyma is believed to intimate about the spreading of inflammation from glomerular to the tubulointerstitial compartment, playing a crucial role in the evolution of both AKI and CKD. ${ }^{56,57}$

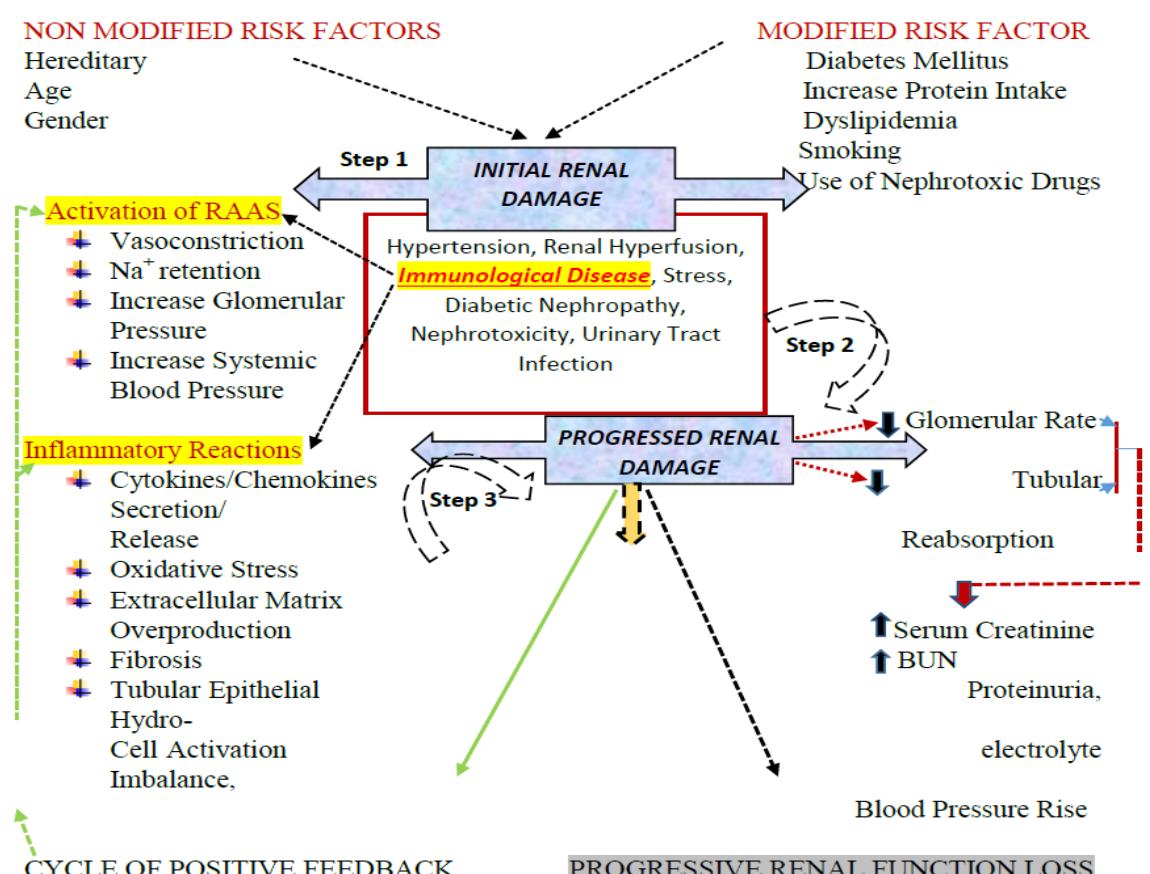

Figure 4. CKD Pathophysiology, (https://www.ncbi.nlm.nih.gov/pmc/articles/PMC8014972/figure/f1-etm-0-0-09969/?report=objectonly) 


\section{HSN Indicator and Parameters}

Our surrounding temperature shows multifactorial dependencies basically on weather conditions, humidity conditions and dew point etc., and among all these situations, human comfortable zone exist between ambient temperature i.e. $20^{\circ} \mathrm{C}$ to $27^{\circ} \mathrm{C}$ and humidity conditions i.e. $35-60 \% .^{5}$ Our human body feel very annoying when these two factors get a tremendous hike and can increase body temperature. Therefore, a gold standard (ISO, 1989) heat stress indicator namely Wet Bulb Globe Temperature (WBGT) technique or instrument has been widely used for analyzing heat stress index and mainly understand human body reactions to heat. ${ }^{58}$ This equipment has been designed from the mutual collaboration of natural wet bulb temperature $\left(\mathrm{T}_{\mathrm{w}}\right)$, black globe temperature $\left(\mathrm{T}_{\mathrm{g}}\right)$ and common air temperature $\left(\mathrm{T}_{\mathrm{a}}\right)$. These three thermometers having a specific role. Tw is calculated within a water wetted cloth which stimulates the heat exchange effect of evaporation from skin covered with sweat and in the similar way $\mathrm{T}_{\mathrm{g}}$ is calculated within the black globe which stimulate the uptake of heat on the skin from solar radiation. These are the various heat stress parameters that show the actual state of our renal system during heat crisis which includes core body temperature, sweat evaporation rate, skin temperature, resting and working phase heart rate, specific gravity of urine, serum creatinine, serum electrolytes, muscle biopsy studies and energy expenditure of the body. ${ }^{37,59}$

The clinical background of heat stress nephropathy give assurance about the close correlation between heart rate and an internal temperature of the human body that supports this fact that ambulatory heart rate monitoring becomes an important indicator of thermal strain. ${ }^{60,61}$ Even though, sweat rate has also been used as physiological strain marker for knowing about the actual hydration status of an individual. ${ }^{62,63}$

\section{Molecular Approaches of HSN}

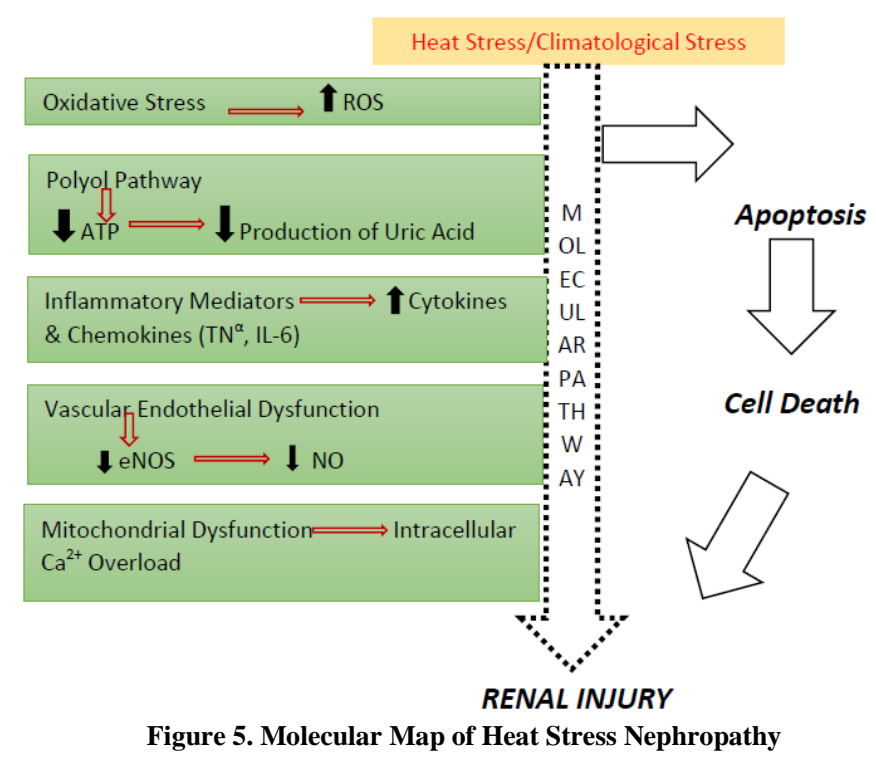

Heat stress nephropathy depends upon multifactorial molecular approaches. Regular episodes of thermal stress along with water shortage and overexertion in the human body associated with four main kinds of pathophysiological changes including Low-grade Rhabdomyolysis ${ }^{64}$,
Hyperosmolarity ${ }^{21,65,66}$,Hyperthermia and extracellular volume depletion. ${ }^{67}$ These pathological changes associated with strong molecular background such as activation of polyol fructokinase pathway, urate crystal formation, long term effect of vasopressin on renal tubules ${ }^{68,69}$ hypokalemia-induced 
renal vasoconstriction and reduction in renal blood flow that may results in ischemic injury. ${ }^{42,70,71,72}$ All these mechanical approaches associated with increased serum and urine osmolality, elevated serum uric acid, elevated fructose and uric acid in the renal cortex, and increased expression of heat shock protein. ${ }^{19,} 73$ Inflammatory mediators also play a vital role in low-grade renal injury associated with the loss of the proximal tubule brush border, increased macrophages and $\mathrm{T}$ lymphocytes in the renal interstitial space and increased interstitial fibrosis and leads towards renal death. $^{74}$ Hyperuricemia is one of the causative factors for heat stress nephropathy showing some important intrarenal hemodynamic effects such as decreasing renal blood flow and increasing glomerular pressure, and finally generating intrarenal oxidative stress, local inflammations and tubular cell injury. ${ }^{18,20,75}$ Figure: 5.

\section{Sugary Beverages and Renal Injury}

Soft drink contains fructose, a monosaccharide that is naturally available in food sources such as fruits and honey and synthetically from sucrose, a disaccharide made up of equal volume of fructose and glucose $^{76}$ are also known local tubular injury, inflammation and oxidative stress when metabolized by the kidney. $77,78,79,80$ Recent studies suggested that worldwide use of added sugars may partially rising frequency of metabolic syndrome, diabetes, hypertension, chronic kidney disease and cardiovascular diseases. ${ }^{81,82,83}$ Fructose harm the kidney by two pathological pathways firstly the increase in the amount of uric acid in response to uric acid production as an end product of fructose metabolism may result in afferent arteriolopathy causing glomerular hypertension ${ }^{84}$ and secondly fructose may also be filtered into the urine where it is taken up in the S3 segment of the proximal tubule results in intracellular generation of uric acid with oxidative stress and inflammation. ${ }^{77}$ Additionally, fructose may also be able to stimulate vasopressin that can intensify the renal injury. ${ }^{85}$ Indeed, a recent clinical study also describes that the rehydration with sugary beverages could activate the markers of renal damage in healthy subjects following exercise in high temperatures. ${ }^{86}$

\section{Ionic Imbalance Associated with Ambient Temperature}

Ionic or electrolyte imbalance is an irregularity in the concentration of electrolytes in the body. Electrolytes play a key role in maintaining homeostasis in the body and also help to regulate heart and kidney function, fluid balance, oxygen delivery, acid-base balance and many more. ${ }^{87}$ Kidney is the most relevant organ associated with fluid and electrolyte balance, and some other factors such as hormonal changes and physiological stress play a supportive role here. ${ }^{88}$ There is a clear theoretical relationship between ambient temperatures and plasma sodium disorders as there is increased sweating and loss of hypotonic fluid collaborate with the situations of impaired thirst sensation or lack of access to water. ${ }^{89}$ Over activation of $\mathrm{Na}+\mathrm{K}+$-ATPase with increase ambient temperature may result in sodium-ion linked fateful pathophysiological conditions such as hypernatremia and hyponatraemia. ${ }^{90}$ Thus, the reciprocal relationship between the temperature (increase temperature) and blood potassium concentration (decrease concentration) may also become the harmful condition for the heat stress nephropathy patients. $^{91}$

\section{Heat Shock Proteins as Biomarkers for Heat Stress}

Heat-shock proteins (HSPs) played an analytical role in the injured or stressed cells and gain a thermo tolerance and ultimately protect the cells from stressinduced cellular damage and also believed to prevent protein aggregation and serve as molecular chaperones. ${ }^{92}$ Extracellular HSPs are concerned with the induction of the cellular immune response while Intracellular HSPs function as molecular chaperones, uphold protein folding and transport 
mechanisms under pathophysiological and physical and chemical stressed condition. ${ }^{93}$ Previous studies show that among various HSPs that are produced during heat stress to protect the cells and DNA damage ${ }^{94,95}$ the HSP 70 genes or proteins may play a remarkable role in controlling cellular responses to stress and apoptosis. ${ }^{96}$ It was noted that the workers who worked in a very high heat conditions had a high level of DNA damage and high HSP 70 level ${ }^{94,97}$ and this HSP 70 was directly linked to molecular recovery that would oppose the injurious effects of the environmental stressors. ${ }^{98}$ By gaining possible qualitative knowledge of plasma and lymphocyte HSPs measurements, we may understand the mechanism of pathogenesis, diagnosis, and prognosis of many diseases to a much greater extent. ${ }^{99,100,101}$ The feasibility of using HSP 70 as a biomarker for genetic damage from heat exposures is an unexplored area in Occupational settings. Though studies have investigated DNA damage and HSP release due to various stressors, very little is known about the expression of HSP 70, its relation with genotoxicity caused by environmental stresses, especially heat, and its possible biomedical significance in pathogenesis processes in humans.

\section{Preventive measures of HSN}

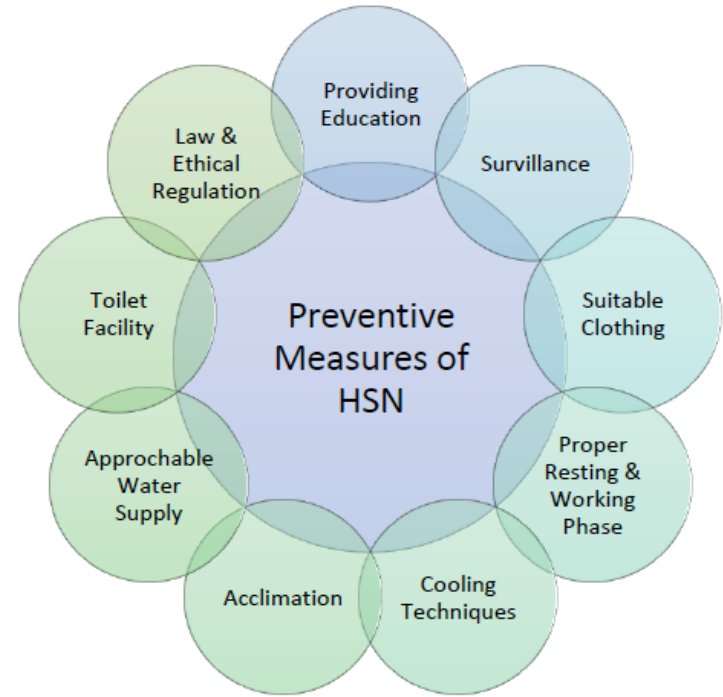

Figure 6. Preventive Measures of Heat Stress Nephropathy (https://els-jbs-prod-

cdn.jbs.elsevierhealth.com/cms/attachment/5030ff89-fa8c-4540b108-23545fd60cfb/gr4.jpg)
Occupational health and safety guidelines have been developed to protect workers and similarly, prevention is the best approach to deal with heat-related CKDassociated mortality ${ }^{33}$ Figure: $6 .{ }^{1}$ Maintaining an adequate supply of water may be the single most prominent intervention in the management of workers exposed to heat stress. ${ }^{102}$ The life-saving measures for a normal population as well as for renal patients include proper water intake, maintain hydration status of body, sponge bath and also by providing the appropriate environment as per the working criteria. ${ }^{103}$ Government preventive policies, pharmacological dose adjustment along with electrolytes and renal function monitoring may also minimize the chances of progression of renal damage. ${ }^{27}$ Besides continuous environmental monitoring, also establish work and rest cycles and developed some appropriate facilities to alleviate heat strain must include toilet facilities, appropriate clothing, and personal cooling techniques. ${ }^{104,105}$ Meanwhile, paying attention towards ethical laws and regulations, buildup the acclimation procedures, digital communication set up processes, early cautioning systems, surveillance, and increase the priority on heat exposure prevention can be a useful tool. ${ }^{106}$ Recent evidences show that implementations of the similar strategies on younger and upcoming susceptible population resulted in improvement of the renal status of an individual with an appropriate hydration status and increased Glomerular Filtration Rate (GFR). ${ }^{24,107}$ One thing has been clearly mentioned in heat stress guidelines i.e. replacing the body fluid periodically $(250 \mathrm{ml} \text { water every } 20 \mathrm{~min})^{108}$ when working in high temperature conditions even though that may lead to heat stress. As we know that, heat exposure reaches upto extreme level during sugar cane cutting, therefore, for safety purpose workers should limit work activities to as short as 15 minutes per hour during part of the day ${ }^{109}$ so better education or counselling for workers in hot environments is clearly 
needed to communicate the risks accompanied with heat exposure and dehydration.

\section{CONCLUSION}

In 21st-century heat stress nephropathy may be acknowledged as a first epidemic due to global warming and becomes a strong pillar of evidence for acute and chronic kidney diseases. Due to climatological variations, the heat-related ailments have been becoming an unsounded cause of deaths worldwide. A regular hike in global temperature or conditions accompanied by decreasing access to portable water supply may also deteriorate the renal injury. Meanwhile, during this crucial time, kidney shows its dual-action i.e. protective one and also becomes the first target site, for heat stress and dehydration associated injury and results in acute kidney damage followed by CKD, electrolyte imbalances, kidney stones etc. The previous clinical studies assured that the heat stress also responsible for genetic damage depends upon the stage of the cell cycle involved. Our review trying to describe the overall perspective of heat stress, their global background, pathophysiology, molecular studies, multifactorial approaches, hightemperature role in nephropathy and the recommended preventive measures of HSN. Meanwhile, the preventive measures criteria depend on the quality standards of assessment of heat stress as well as on modernization of technology such as specially designed cooling clothing, ventilation solutions, and renewable energy cooling systems. This review focus on the innovative collaboration between the health sector and the technology sector. This review also enlightened the fact that HSP periodic measurements may also become a biomarker for study the DNA or cell damage during high heat exposure and may also become a preventive tool in the future treatment of HSN. Therefore, this is the demand of an era that the engineers, researchers, health authorities and all government sectors, they make a fruitful collaboration for the development of the healthy nation. Prevention plans and strategies have to be created and updated time to time for treating occupational heat stress and raise the awareness among the working population and the health care workers to mitigate the outcomes of climate changes, which will ultimately promote the research and technological development.

\section{Acknowledgement: None}

\section{Conflict of Interest: None}

\section{Source of Funding: None}

\section{REFERENCES}

1. Fabiana B, Nerbass, Roberto PF, et al. Occupational heat stress and kidney health: from farms to factories. Kidney Int Rep. 2017; 2: 998-1008.

2. World Health Organization. Launch of special initiative to address climate change impact on health in Small Island Developing States. Bonn: World Health Organization. https://www.who.int/news/item/12-11-2017launch-of-special-initiative-to-addressclimate-change-impact-on-health-in-smallisland-developing-states.

3. Stefan R, Dim C. Increase of extreme events in a warming world. Proc Natl Acad Sci USA. 2011; 108(44): 17905-17909.

4. Fischer EM, Knutti R. Anthropogenic contribution to global occurrence of heavy precipitation and high temperature extremes. Nat Clim Chang. 2015; 5: 560.

5. Kovats RS, Shakoor H. Heat Stress and Public Health: A Critical Review. Annual Review of Public Health. 2008; 29: 41-55.

6. Owen D. CDC will explore kidney failure epidemic among agricultural workers. BMJ. 2014; 348: 3385.

7. Dash SK, Kjellstrom T. Workplace heat stress in the context of rising temperature in India. Curr Sci. 2011; 101: 496-503.

8. Krishnan S, Maruthy KN, Vidhya V, et al. Research in occupational heat stress in India: Challenges and opportunities. Indian Journal of Occupational and Environmental Medicine. 2016; 20(2): 73-78.

9. Ken P. Human Thermal Environments: The Effects of Hot, Moderate and Cold Environments on Human Health, Comfort 
and Performance. New York, CRC Press, 2002: 1-16.

10. Pranab KN, Anjali N, Shirish PA. Thermal limits of men in moderate to heavy work in tropical farming. Ind Health. 2007; 45: 107-117.

11. Kerry G, Harrington JM. Occupational Hygiene. The Thermal Environmental. $3^{\text {rd }}$ edition. Birmingham: Wiley Publication; 2008.

12. Sigurbjorn AA, Darby SP, Matthew GS, et al. Cooling vest worn during active warmup improves $5-\mathrm{km}$ run performance in the heat. Journal of applied physiology. 2004; 96(5): 1867-1874.

13. Jose GS, Craig GC, John MJ. The cardiovascular challenge of exercising in the heat. The Journal of physiology. 2008; 586(1): 45-53.

14. Veronica M, Graham B, John DS, et al. Self-pacing as a protective mechanism against the effects of heat stress. Annals of occupational hygiene. 2011; 55(5): 548-555.

15. Masaki I, Andrew EL, Shuo HC, et al. Heat Stress and Cardiovascular, Hormonal, and Heat Shock Proteins in Humans. Journal of Athletic Training. 2012; 47(2): 184-190.

16. Fang $\mathrm{Z}$, Feng W, Fangze Li, et al. Association of HSP70 and genotoxic damage in lymphocytes of workers exposed to Coke- oven emission. Cell stress Chaperones. 2002; 7 (4): 396-402.

17. Carlos A, Yuka S, Tamara M, et al. Experimental heat stress nephropathy and liver injury are improved by allopurinol. Am J Physiol Renal Physiol. 2018; 315: 726-733.

18. Laura G, Virgilia S, Edilia T, et al. Role of oxidative stress in the renal abnormalities induced by experimental hyperuricemia. Am J Physiol Renal Physiol. 2008; 295: 1134-1141.

19. Eun SR, Mi JK, Hyun SS, et al. Uric acidinduced phenotypic transition of renal tubular cells as a novel mechanism of chronic kidney disease. Am J Physiol Renal Physiol. 2013; 304: 471-480.

20. Sanchez LG, Lanaspa MA, Cristobal GM, et al. Uric acid-induced endothelial dysfunction is associated with mitochondrial alterations and decreased intracellular ATP concentrations nephron. Exp Nephrol. 2012; 121: 71-78.

21. Richard JJ, Bernardo RI, Carlos RJ, et al. Hyperosmolarity drives hypertension and
CKD-water and salt revisited. Nat Rev Nephrol. 2014; 10:415-420.

22. Amin H, Ali K, Samaeeh M, et al. Ameliorative effect of ferulic acid on gentamicin induced nephrotoxicity in a rat model; role of antioxidant effects. Nutritional Health Research Centre. 2018; 7:73-77.

23. Lizzie D. Karachi heat wave: Death toll tops 1,000 as government and electricity company trade blame [Internet]. 2015 [updated 2015 June; cited 2020 June 30]. Available from: https://www.independent.co.uk/news/world/ asia/pakistan-heatwave-death-toll-tops1000as-government-and-electricity-companytrade-blame 10344719.html.

24. David HW, Jenny A, Matteo B, et al. Intervention to diminish dehydration and kidney damage among sugarcane workers. Scand J Work Environ Health. 2018; 44:1624.

25. Bodin T, Garcia R, Weiss I, et al. Intervention to reduce heat stress and improve efficiency among sugarcane workers in El Salvador: Phase 1. Occup Environ Med. 2016; 73:409-16.

26. Flynn A, McGreevy C, Mulkerrin EC. Why do older patients die in a heat wave? QJM. 2005; 98:227-229.

27. Fiona JG, Robert MG, Michael E et al, Endemic Nephropathy around the World. Kidney Int Rep. 2017; 2: 282-292.

28. Ministerio AP, Alimentacion MA [Internet]. 2016[updated 2016 June; cited 2020 June 30]. Available from: www.magrama.gob.es.

29. Nick W, Markus A, Sonja AK, et al. The Lancet Countdown on health and climate change: from 25 years of inaction to a global transformation for public health. Lancet. 2018 Feb 10; 391(10120):581-630.

30. Agencia Estatal de Meteorologia [Internet].2016 [Updated 2016 June 10; cited 2020 June 30]. Available from: www.aemet.es.

31. Haigong W, Mohsen N, Christine A, et al. Global, regional, and national life expectancy, all-cause mortality, and causespecific mortality for 249 causes of death, 1980-2015: a systematic analysis for the Global Burden of Disease Study 2015. Lancet. 2016; 388: 1459-544.

32. Marcel GM, Rene JF, Jurgen AH. Heat waves and dehydration in the elderly. BMJ. 2009; 339: 2663. 
33. Lundgren K, Karin K, Kalev G, et al. Effects of heat stress on working populations when facing climate change. Ind Health. 2013; 51:3-15.

34. Victoria State Government. Extreme heat and heat waves. Available from: https://www2.health.vic.gov.au/publichealth/environmental-health/climateweather-and-public-health/heatwaves-andextreme-heat. Accessed on 24 July 2016.

35. Dematte JE, Mara KO, Buescher J, et al. Near-fatal heat stroke during the 1995 heat wave in Chicago. Ann Intern Med. 1998; 129(3): 173-181.

36. Seema M. The evaluation and management of heat injuries in an intensive care unit. Indian J Crit Care Med. 2015; 19(8):479483.

37. Anonymous. India Heat Wave Kills More Than 1,400; Temperatures Soar to 118 Degrees. Available from: https://weather.com/news/news/indiaheatwave- latest-news.

38. Roncal JC., Lanaspa MA, Jensen T, et al. Mechanisms by which dehydration may lead to chronic kidney disease. Ann Nutr Metab. 2015; 66(3):10-13.

39. Daniel EW, Michael DM, James SK, et al. Daniel R Brooks. The Central American epidemic of CKD. Clin J Am Soc Nephrol. 2013; 8:504-511.

40. Catharina W, Jennifer C, Christer H, et al. Resolving the enigma of the mesoamerican nephropathy: a research workshop summary. Am J Kidney Dis. 2014; 63:396404.

41. Ubiratan PS, Dirce TZ, Mario TF, et al. Burnt sugarcane harvesting is associated with acute renal dysfunction. Kidney Int. 2015; 87:792-799.

42. Jason G, Jay L, Balaji R, et al. Climate change and the emergent epidemic of CKD from heat stress in rural communities: the case for heat stress nephropathy. Clin J Am Soc Nephrol. 2016; 11:1472-1483.

43. Rebecca LL, Daniel RB, Juan JA, et al. Biomarkers of kidney injury among Nicaraguan sugarcane workers. Am J Kidney Dis. 2015; 67:209-217.

44. Anderson S. Mechanisms of injury in progressive renal disease. Experimental Nephrology Supplement. 1996 Jan 1; 1:3440.

45. Sarah LW, Steven JC, Stephen J, et al. How can we achieve global equity in provision of renal replacement therapy? Bulletin of the World Health Organization. 2008; 86(3):229-237.

46. Daniela M, Daniela GB, Adrian T et al, Impact of adipose tissue in chronic kidney disease development. Experimental and therapeutic medicine. 2021; 21: 539.

47. Irene LN, Clarice KF, Roberto Z. The inflammatory component in progressive renal disease-Are interventions possible? Nephrology Dialysis Transplantation. 2002; 17(3):363-368.

48. Michael Z, Eric GN. Mechanisms of tubulointerstitial fibrosis. Journal of the American Society of Nephrology. 2010; 21:1819-1834.

49. Christiane R, Gunter W. Renin-angiotensinaldosterone system and progression of renal disease. Journal of the American Society of Nephrology. 2006; 17:2985-2991.

50. Flavia GM, Elizabete PB, Camilla F, et al. AT1 blockade during lactation as a model of chronic nephropathy: Mechanisms of renal injury. American Journal of Physiology Renal Physiology. 2008; 294:1345-1353.

51. Miguel LG, Rita CC, Humberto D, et al. Intrarenal renin-angiotensin system is up regulated in experimental model of progressive renal disease induced by chronic inhibition of nitric oxide synthesis. Journal of the American Society of Nephrology. 2004; 15:1805-1815.

52. Fanelli C, Fernandes BH, Machado FG, et al. Effects of losartan, in monotherapy or in association with hydrochlorothiazide, in chronic nephropathy resulting from losartan treatment during lactation. American Journal of Physiology Renal Physiology. 2011; 301(1):580-587.

53. Gunter W, Ulrich OW. Angiotensin II and cell cycle regulation. Hypertension. 2004; 43:693-698.

54. LL Wu, Yang N, Roe CJ, et al. Macrophage and myofibroblasts proliferation in remnant kidney: Role of angiotensin II. Kidney International Supplement. 1997; 63:221225.

55. Helmy MS, Robert MC. Role of the intrarenal renin-angiotensin-aldosterone system in chronic kidney disease. American Journal of Nephrology. 2010; 31:541-555.

56. Katharina H, Andre T, Christian K. Kidney dendritic cells in acute and chronic renal disease. International Journal of Experimental Pathology. 2011; 92:193-201. 
57. Christian K, Ulf P, Anders HJ, et al. The immune system and kidney disease: Basic concepts and clinical implications. Nature Reviews Immunology. 2013; 13:738-753.

58. Bernard TE, Pourmoghani M. Prediction of workplace wet bulb global temperature. Appl Occup Environ Hyg. 999; 14:126-134.

59. Benjawan T, Vasoontara Y, Tord K, et al. Heat stress, health and well-being: Findings from a large national cohort of Thai adults. BMJ Open. 2012; 2(6): 001396.

60. Derrick JB, Graham PB. Deep body core temperatures in industrial workers under thermal stress. J Occup Environ Med. 2002; 44:125-135.

61. Ikuharu M, Nobuyuki M, Kazuhisa M. Hot environment and health problems of outdoor workers at a construction site. Ind Health. 2006; 44:474-480.

62. Graham PB, John S. Hydration status and physiological workload of UAE construction workers: A prospective longitudinal observational study. J Occup Med Toxicol. 2008; 3:21

63. Graham PB, Veronica SM. Sweat rate and sodium loss during work in the heat. $\mathrm{J}$ Occup Med Toxicol. 2008; 3:4.

64. Vanholder R, Sever MS, Erek E. Rhabdomyolysis. J Am Soc Nephrol. 2000; 11: 1553-1561.

65. Carlos RJ, Takuji I, Miguel AL, et al. Fructokinase activity mediates dehydration induced renal injury. Kidney Int. 2014; 86: 294-302.

66. Carlos AR, Yuka S, Tamara M, et al. Heat stress nephropathy from exercise-induced uric acid crystalluria: a perspective on mesoamerican nephropathy. Am J Kidney Dis. 2016; 67: 20-30.

67. Ricardo CR, Catharina W, Richard JJ. CKD of unknown origin in Central America: the case for a mesoamerican nephropathy. Am J Kidney Dis. 2014; 63:506-520.

68. Lise B, Nadine B, Eberhard R. Vasopressin: a novel target for the prevention and retardation of kidney disease? Nat Rev Nephrol. 2013; 9:223-239.

69. Clark WF, Sontrop JM, Huang SH, et al. Hydration and Chronic Kidney Disease Progression: A Critical Review of the Evidence. Am J Nephrol. 2016; 43:281292.

70. Ramon GT, Emmanuel J, Catharina W, et al. Heat stress, dehydration, and kidney function in sugarcane cutters in $\mathrm{El}$
Salvador-A cross-shift study of workers at risk of mesoamerican nephropathy. Environ Res. 2015; 142:746-755.

71. Kupferman J, Amador JJ, Lynch KE, et al. Characterization of Mesoamerican nephropathy in a kidney failure hotspot in Nicaragua. Am J Kidney Dis. 2016; 68:716725.

72. Catharina W, Aurora A, Marvin G, et al. Heat stress, hydration and uric acid: a crosssectional study in workers of three occupations in a hotspot of Mesoamerican nephropathy in Nicaragua. BMJ Open. 2016; 6(12): 011034.

73. Duk HK, Takahiko N, Lili F, et al. A role for uric acid in the progression of renal disease. J Am Soc Nephrol. 2002; 13: 28882897.

74. David LM. Heat stress nephropathy and hyperuricemia. Am J Physiol Renal Physiol. 2018; 315: 757-758.

75. Laura GS, Edilia T, Carmen AC, et al. Mild hyperuricemia induces glomerular hypertension in normal rats. Am J Physiol Renal Physiol. 2002; 283:1105-1110.

76. Marek K, Richard JJ, Takuji I, et al. The Impact of Fructose on Renal Function and Blood Pressure. International Journal of Nephrology. 2011; 2011:5.

77. Pietro C, Michael SG, Wei M, et al. Keto hexokinase dependent metabolism of fructose induces proinflammatory mediators in proximal tubular cells. J Am Soc Nephrol. 2009; 20(3):545-553.

78. Magdalena M, Santos EP, Diana J, et al. Dietary fructose and hypertension. Current Hypertension Reports. 2011; 13(1): 29-35.

79. Bruckdorfer KR, Khan IH, Yudkin J. Dietary carbohydrate and fatty acid synthetase activity in rat liver and adipose tissue. Biochemical Journal. 1971; 123(1):7.

80. Takahiro N, Tomoki K, Michael G, et al. Dietary fructose causes tubulointerstitial injury in the normal rat kidney. American Journal of Physiology Renal Physiology. 2010; 298(3): 712-720.

81. Richard JJ, Mark SS, Yuri S, et al. Potential role of sugar (fructose) in the epidemic of hypertension, obesity and the metabolic syndrome, diabetes, kidney disease, and cardiovascular disease. American Journal of Clinical Nutrition. 2007; 86(4), 899-906.

82. Tappy L, Kim L. Metabolic effects of fructose and the worldwide increase in 
obesity. Physiological Reviews. 2010; 90(1): 23-46.

83. Peter JH. Dietary fructose: implications for dysregulation of energy homeostasis and lipid/carbohydrate metabolism. Nutrition Reviews. 2005; 63(5):133-137.

84. Laura GS, Edilia T, Adriana $\mathrm{J}$, et al. Fructose induced metabolic syndrome is associated with glomerular hypertension and renal microvascular damage in rats. American Journal of Physiology Renal Physiology. 2007; 292(1): 423-429.

85. Carlos AR, Tamara M, Ana AH, et al. Effects of exogenous desmopressin on a model of heat stress nephropathy in mice. Am J Physiol Renal Physiol. 2017; 312(3):418-426.

86. Christopher LC, Blair DJ, James RS, et al. Soft drink consumption during and following exercise in the heat elevates biomarkers of acute kidney injury. Am J Physiol Regul Integr Comp Physiol. 2019; 316(3):189-198.

87. Khalid OA, Samrein BM, Muntaser EI, et al. The Interplay of Dysregulated $\mathrm{pH}$ and Electrolyte Imbalance in Cancer. Cancers. 2020; 12 (4):898.

88. Arif KB, Ozlem K, Ataman $\mathrm{K}$, et al. General characteristics of patients with electrolyte imbalance admitted to emergency department. World Journal of Emergency Medicine. 2013; 4 (2):113-116.

89. Alberto L, Fernando L. High temperatures and nephrology: the climate change problem. Nefrologia. 2017; 37(5): 492-500.

90. Ravinder S, Andrew SD, Elizabeth H, et al. The phenomenon of seasonal pseudo hypokalemia: effects of ambient temperature, plasma glucose and role for sodium-potassium-exchanging-ATPase.

Clin Biochem. 2009; 42:813-818.

91. Rosemary D, Christopher JT, Mark S. Hyponatraemia- presentations and management. Clinical Medicine. 2017; 17(3):263-269.

92. Yan YE, Yong $\mathrm{Z}$, Wang $\mathrm{H}$, et al. Pathophysiological factors underlying heatstroke. Med Hypotheses. 2006; 67(3):609-617.

93. Ahlgrim C, Pottgiesser T, Robinson N, et al. Are $10 \mathrm{~min}$ of seating enough to guarantee stable haemoglobin and haematocrit readings for the athlete's biological passport? Int J Lab Hematol. 2010; 32(5): 506-511.
94. Landry J, Bernier D, Chretien P, et al. Synthesis and degradation of heat shock proteins during development and decay of thermo tolerance. Cancer Research. 1982; 42(6):2457-2461.

95. Li GC, Werb Z. Correlation between synthesis of heat shock proteins and development of thermo tolerance in Chinese hamster fibroblasts. Proc Natl Acad Sci USA. 1982; 79:3218-3322.

96. Li GC, Li L, Lee WE. Heat shock protein HSP70 protects cells from thermal stress even after deletion of its ATP-binding domain. Proceedings of the National Academy of Sciences. 1992; 89(6):20362040.

97. Pelham HR. Hsp70 accelerates the recovery of nucleolar morphology after heat shock. The EMBO Journal. 1984; 3(13):3095.

98. Barnes JA, Collins BW, Dix DJ, et al. Effects of heat shock protein 70 (HSP70) on arsenite-induced genotoxicity. Environmental and molecular mutagenesis. 2002; 40(4):236-242.

99. Jin X, Wang R, Xiao C, et al. Serum and lymphocyte levels of Hsp7l in aging: a study in the normal Chinese population. Cell Stress Chaperones. 2004; 9(1):69-75.

100. Jin X, Xiao C, Tanguay RM, et al. Correlation of lymphocyte heat shock protein 70 levels with neurologic deficits in elderly patients with cerebral infarction. The American journal of medicine. 2004; 117(6):406-11.

101. Jurgen R, Gabriele M. Immunostimulatory functions of membranebound and exported heat shock protein 70 . Exerc Immunol Rev. 2005; 11:17-33.

102. Wisit C, Sandro R, Keith F, et al. Treatment effect, adherence, and safety of high fluid intake for the prevention of incident and recurrent kidney stones: a systematic review and meta-analysis. J Nephrol. 2016; 29:211-219.

103. Tomas O, Flatharta, Aidan F, et al. Heat-related chronic kidney disease mortality in the young and old: differing mechanisms, potentially similar solutions? BMJ Evidence-Based Medicine. 2019; 24:45-47.

104. Kjellstrom T, Crowe J. Climate change, workplace heat exposure, and occupational health and productivity in Central America. Int J Occup Environ Health. 2011; 17:270281. 
105. Vidhya V, Shanmugam R, Krishnamoorthy $\mathbf{M}$, et al. Heat stress and inadequate sanitary facilities at workplaces: an occupational health concern for women? Glob Health Action. 2016; 1:1-9.

106. Paul AS, HeeKyoung C. Climate change and occupational safety and health: establishing a preliminary framework. J Occup Environ Hyg. 2009; 6:542-554.

107. Bodin T, Garcia R, Weiss I, et al. Intervention to reduce heat stress and improve efficiency among sugarcane workers in El Salvador: Phase 1. Occup Environ Med. 2016; 73: 409-16.

108. U.S. Department of Health and Human Services. Centers for Disease Control and
Prevention, National Institute for Occupational Safety and Health. NIOSH criteria for a recommended standard: occupational exposure to heat and hot environments. Cincinnati: NIOSH, 2016.

109. Jennifer C, Catharina W, Bryan RS, et al. Heat exposure in sugarcane harvesters in Costa Rica. Am J Ind Med. 2013; 56: 11571164.

How to cite this article: Jaswal P, Priyanka, Basu J. Climatological nephropathy: an overview. Int J Health Sci Res. 2021; 11(9): 83-96. DOI: https://doi.org/10.52403/ijhsr. 20210913 